\title{
Pulmonary effects of passive smoking: the Indian experience
}

\author{
Gupta D, Aggarwal AN, Jindal SK \\ Department of Pulmonary Medicine, Postgraduate Institute of Medical Education \\ and Research, Chandigarh, India
}

\begin{abstract}
There are only a few studies done on pulmonary effects of passive smoking from India, which are summarized in this paper. Several vernacular tobacco products are used in India, bidis (beedis) being the commonest form of these. Bidis contain a higher concentration of nicotine and other tobacco alkaloids compared to the standard cigarettes (e.g., the sum of total nicotine and minor tobacco alkaloids was $37.5 \mathrm{mg}$ in bidi compared to $14-16 \mathrm{mg}$ in Indian or American cigarettes in one study). A large study performed on 9090 adolescent school children demonstrated environmental tobacco smoke (ETS) exposure to be associated with an increased risk of asthma. The odds ratio for being asthmatic in ETSexposed as compared to ETS-unexposed children was 1.78 (95\% CI: 1.33-2.31). Nearly one third of the children in this study reported non-specific respiratory symptoms and the ETS exposure was found to be positively associated with the prevalence of each symptom. Passive smoking was also shown to increase morbidity and to worsen the control of asthma among adults. Another study demonstrated exposure to ETS was a significant trigger for acute exacerbation of asthma. Increased bronchial hyper-responsiveness was also demonstrated among the healthy nonsmoking adult women exposed to ETS. Passive smoking leads to subtle changes in airflow mechanics. In a study among 50 healthy nonsmoking women passively exposed to tobacco smoke and matched for age with 50 unexposed women, forced expiratory volume in first second (FEV1) and peak expiratory flow (PEF) were marginally lower among the passive smokers (mean difference $0.13 \mathrm{~L}$ and $0.20 \mathrm{~L}-1$, respectively), but maximal mid expiratory flow (FEF25-75\%), airway resistance (Raw) and specific conductance (sGaw) were significantly impaired. An association between passive smoking and lung cancer has also been described. In a study conducted in association with the International Agency for Research on Cancer, the exposure to ETS during childhood was strongly associated with an enhanced incidence of lung cancer ( $\mathrm{OR}=3.9,95 \% \mathrm{CI}$ 1.9-8.2). In conclusions several adverse pulmonary effects of passive smoking, similar to those described from the western and developed countries, have been described from India.
\end{abstract}

KEY wORDS: Environmental tobacco smoke, ETS exposure, pulmonary effects, lung function.

Received April 15, 2002; Revised May 22, 2002; Accepted June 7, 2002

Correspondence: Dr. Dheeraj Gupta M.D., D.M., FCCP, Associate Professor,

Department of Pulmonary Medicine, Postgraduate Institute of Medical Education and Research Chandigarh 160 012, India

Email: dgupta@glide.net.in

Tel: +91 (172) 747-585 (ext. 391), Fax: +91 (172) 745-959 


\section{INTRODUCTION}

Passive smoking or environmental tobacco smoke (ETS) exposure has been variously described as 'second-hand smoke' or 'involuntary smoking'. In the past, little attention, beyond its nuisance effect, was paid to the health consequences of passive smoking. Exhaustive report on health consequences of involuntary smoking by the United States Surgeon General [1] and reports by the United States Environmental Protection Agency [2] highlighted the increased risks of several diseases similar to those seen among smokers, in persons exposed to ETS at home or at work place. Several hundred studies were quoted in these reports, which cited various pulmonary and extra-pulmonary health effects of passive smoking. But most of these studies were reported from the Western and developed countries. There are very few reports on the health effects of passive smoking from the developing and the underdeveloped countries.

Smoking is on the rise in developing countries although there are differences in tobacco products, quality of tobacco used and the smoking practices [3]. Environmental conditions such as the overcrowding and the poor ventilation at homes and work places may make the health effects of ETS more pronounced. There are a few studies on pulmonary effects of passive smoking from India. In this paper, we review the published information available from India on pulmonary effects of passive smoking.

\section{COMPOSITION OF ETS}

Tobacco smoke contains over 4000 chemicals in the forms of particles and gases [2]. ETS is a combination of sidestream (SS) smoke emitted from the burning end of a cigarette and the remainder of mainstream (MS) smoke exhaled by a smoker. The sidestream smoke constitutes about $85 \%$ of the smoke present in the room where active smokers smoke, and contains many potentially toxic components, some of which may occur in even higher concentrations than in the mainstream smoke [4]. The particulate phase consists of tar (itself composed of many chemicals), nicotine, benzo( $a$ )pyrene, and hundreds of other noxious compounds. A few examples of gases in tobacco smoke are carbon monoxide, benzene, ammonia, dimethylnitrosamine, formaldehyde, hydrogen cyanide and acrolein. Some of these constituents have marked irritant properties and there are found to be about 60 known or suspected human carcinogens present in tobacco smoke. The environmental tobacco smoke has been classified as class A (known for human) carcinogen along with asbestos, arsenic, benzene and radon gas [5].

The most popular Indian smoking product is "bidi" (also spelled as beedi). Bidis are made of crude sun-dried tobacco wrapped in a dried Tendu (Dyospyros melanoxylon) leaf. Another smoking product used in different parts of India is "chillum" or "hooka", which resembles a pipe made of clay. Tobacco is burnt along with molasses and coal, and smoked either directly or through a long pipe with smoke passing through a water container. The amount of nicotine and tobacco alkaloids present in the mainstream smoke (MS) of these vernacular tobacco products is likely to be different from those present in the MS of standard cigarettes because of the differences in their design (e.g. water acts as a filter in hooka and no filter exists in most bidis). The sidestream (SS) smoke released from such products is also likely to be different from the SS of standard cigarettes due to differences in tobacco processing, burning rate and temperature, and the use of additives for burning tobacco. In a study from Mumbai, the bidi, an Indian cigarette and a brand of American cigarette were analyzed by gas chromatography-flame ionization detection for the levels of nicotine and minor tobacco alkaloids in the MS and SS smoke [6]. The analysis demonstrated higher total nicotine and minor tobacco alkaloids in tobacco from bidi $(37.7 \mathrm{mg} / \mathrm{g})$ compared to Indian or American cigarettes (14-16 mg/g). This study also demonstrated higher delivery of nicotine and alkaloids by bidi as evidenced by higher concentration of nicotine in the MS smoke (MS/SS) compared to that released by a regular cigarette. In another study from Mumbai, air samples from different indoor environments were analyzed for the levels of various volatile organic compounds. A very high level of benzene was detected in a smoker's room and in a kitchen using kerosene as fuel [7].

\section{QUANTIFYING PASSIVE SMOKING}

One of the very difficult tasks in most studies on passive smoking is to quantify an ETS exposure. Most epidemiological studies of ETS depend largely on the validity of self-reported exposure. In a large multi-country collaborative study, which included Chandigarh as one of the collaborating centers, the self-reported ETS exposure among nonsmoking women married to smokers at home or at work was evaluated. This study was conducted in 13 centers across 10 countries and included 1,369 nonsmoking married women. Urinary cotinine levels were measured and correlated with the history of ETS exposure. It was demonstrated that nonsmoking women could provide appropriate estimates of their exposure, which well correlated with their biochemically measured exposure levels. The results of a linear regression analysis indicated that the duration of exposure and the number of cigarettes to which the subjects reported to be exposed were strongly correlated with the levels of urinary cotinine excretion. The number of ciga- 
rettes was the best measure of exposure to husbands' smoking, while exposure at workplace was more strongly related to the duration of exposure [8]. It was also shown that the potential bias due to smoker misclassification was very unlikely to be responsible for the increased health risks observed in the epidemiological studies on ETS [9].

\section{PASSIVE SMOKING AND LUNG FUNCTIONS}

There is a biological plausibility that passive smoking can affect the pulmonary functions similar to the effects of active smoking. There are only a few cross-sectional and longitudinal studies that have shown ETS exposure as an important risk factor for obstructive lung disease with a significant dose response relationship [10,11]. Controlled acute exposure to ETS also results in some decrements in lung volumes and flows [12].

In a study from Chandigarh on 200 school children, the effects of passive smoking and domestic cooking fuels on lung function were evaluated. It was observed that spirometric indices were lower in children exposed to biomass fuels vis-avis liquid petroleum gas at home. All the indices studied such as vital capacity (VC), forced expiratory volume in first second $\left(\mathrm{FEV}_{1}\right), \mathrm{FEV}_{1} / \mathrm{VC}$ ratio, peak expiratory flow (PEF) and maximal mid expiratory flow $\left(\mathrm{FEF}_{25-75 \%}\right)$ were also lower among passive smokers, though statistically significant difference was observed only in mid expiratory flows among children exposed to mixed fuels [13].

Recently, we have also studied airflow mechanics in asymptomatic healthy women to evaluate the effects of longterm exposure to ETS (unpublished data). Lung functions [including $\mathrm{VC}, \mathrm{FEV}_{1}, \mathrm{FEV}_{1} / \mathrm{VC}$ ratio, $\mathrm{PEF}, \mathrm{FEF}_{25-75 \% \text {, air- }}$ way resistance $\left(\mathrm{R}_{\mathrm{aw}}\right)$ and specific conductance $\left(\mathrm{sG}_{\mathrm{aw}}\right)$ ] were compared among 50 healthy nonsmoking women exposed to passive smoking (Group I) and age matched 50 women not similarly exposed (Group II). Conditional and logistic linear regression analyses were performed to assess contribution of household ETS-exposure to decreased lung function after adjusting for potential confounders. The results have demonstrated that although $\mathrm{FEV}_{1}$ and PEF of passive smokers were only marginally lower than the controls (mean difference $0.13 \mathrm{~L}$ and $0.20 \mathrm{~L}^{-1}$ respectively), their $\mathrm{FEF}_{25-75 \% \text {, }}$, $\mathrm{R}_{\mathrm{aw}}$ and $\mathrm{sG}_{\mathrm{aw}}$ were significantly impaired. Ten $(20 \%)$ women exposed to ETS and five (10\%) unexposed had abnormal $\mathrm{R}_{\mathrm{aw}}$ (adjusted odds ratio $6.72,95 \%$ confidence interval 1.15-39.42), while eight (16.0\%) women in group I and only $1(2 \%)$ in group II had abnormal sG $\mathrm{saw}_{\text {aw }}$ (adjusted odds ratio $21.08,95 \% \mathrm{CI}=1.30-341.05$ ).

Bronchial hyper responsiveness (BHR) is an important determinant of decline in lung function in normal subjects and those with chronic bronchitis [14]. Parental smoking has shown to be associated with BHR in children [15]. We have studied BHR, as measured by methacholine broncho-provocation test, in three groups of nonsmoking housewives with or without history of exposure to ETS or biomass fuel combustion [16]. The first group comprised of 60 controls, all being nonsmokers with no history of chronic exposure to environmental tobacco smoke (ETS) or biomass fuels. Three of these women showed a 20 per cent $\mathrm{FEV}_{1}$ fall with a cumulative methacholine dose of $72.5 \mathrm{mg}$ or less. Of 60 women in group II (ETSexposed) and 52 in group III (biomass fuel exposed), 26 $(43.3 \%)$ and $10(19.2 \%)$ showed bronchial BHR, respectively. The odds ratios for BHR in groups II and III were 14.53 and 4.52 , respectively, compared to controls. The number of hyperresponders was significantly more and the mean $\mathrm{PD}_{20}$ was less among the exposed than among the unexposed group. The occurrence of BHR was more evident among the ETS-exposed group $(\mathrm{P}<0.05)$ than among the biomass-combustion group. There were more hyper-responders among group II and those who had an overall higher cumulative exposure as measured by an exposure index of 50 or more [exposure index (EI) is equal to an average daily number of cigarettes or bidis to which exposure is reported, multiplied by the number of years during which such an exposure occurred], compared to those with EI of less than 50. An ETS-exposure may thus either unmask the inherent BHR or sensitize hitherto non-reactive airways.

Passive smoking can cause subtle changes in lung function. Several earlier studies have also shown similar findings. The magnitude of reported changes, however, has been small both in cross-sectional and longitudinal studies. Some investigators have reported a significant decrease in $\mathrm{FEV}_{1}[17,18]$, while some others have documented non-significant lower values $[19,20]$. A significant decrement in the mid-expiratory flow rates observed in our studies on both children and adult women, points towards narrowing of the small airways in a fashion similar to the known observations among active smokers [21]. However, larger longitudinal trials are needed to evaluate progression of this impairment with continued exposure to ETS.

\section{PASSIVE SMOKING AND ASTHMA}

The noxious effects of passive smoking on asthma are frequently described and debated. Passive smoking has been linked to the causation, increased morbidity and acute exacerbation of asthma [22].

The role of ETS in causing asthma has now been worldwide accepted. The International Consultation on Environmental Tobacco Smoke (ETS) and Child Health held in Geneva, Switzerland, concluded that ETS exposure causes a 
wide variety of adverse health effects in children, including lower respiratory tract infections such as pneumonia and bronchitis, coughing and wheezing, initiation and worsening of asthma, and middle ear disease [23]. Cross sectional studies have consistently revealed a detrimental effect of parental smoking, especially maternal, on lung function and/or severity of asthma in children [24]. There are increases in both prevalence and severity of asthma in children exposed to ETS from parental smoking. We have conducted a large community based survey for prevalence of asthma among adolescent school children in Chandigarh [25]. Using a previously standardized questionnaire [26], data from 9090 students in the 9 to 20 year age range were analyzed. There were 4367 (48\%) boys, among whom the observed prevalence of asthma was 2.6\%. Among $4723(52 \%)$ girls, asthma was present in 90 $(1.9 \%)$ students. A greater number of asthmatic students had either smoking parents or other family members who smoked at home as compared to non-asthmatics $(41 \%$ vs. $28 \%$, p < 0.0001). The odds ratio for being asthmatic for patients exposed to ETS compared to unexposed patients was 1.78 (95\% confidence interval 1.33-2.31). Another study from the neighbouring state of Haryana, involved 2000 school children in rural settings using the International Study of Asthma and Allergy in Children (ISAAC) questionnaire [27]. Among these, forty children were found to be asthmatic. Each asthmatic child was matched with two healthy kids of the same age and sex from the same study population. An in-depth interview on possible risk factors was done for each case and its controls. The results of the multivariable analyses have shown that passive smoking was an important risk factor associated with asthma (OR 3.33, 95\% CI $=1.85-7.65)$, besides the other factors such as having pets at home and the absence of windows in living rooms [28]. However, a smaller hospital based study in children from Delhi, failed to show any significant risk of developing asthma with passive smoking [29]. Conceptually, children, whose respiratory and immune systems are in the developing state, are more vulnerable than adults to ETS exposure [30]. Children also spend more time at home and get exposed to smoking from parents. In a meta-analysis, the pooled odd's ratio for asthma prevalence from 14 case control studies was 1.37 (95\% CI 1.15-1.64) [31]. The International Consultation report referring to this latter has also concluded that both asthma and respiratory symptoms (wheeze, cough, breathlessness and phlegm) are indeed increased among children whose parents smoke; the results of over 60 studies on school-aged children have shown that the pooled relative risks for either parent smoking range from 1.2 to 1.4 [23].

ETS has adverse effects on asthmatic adults too. Various observational studies have reported worsening or precipitation of respiratory and nasal symptoms, cough and wheeze on exposure to ETS in allergic individuals [32]. One of the earli- est studies documenting adverse effects of passive smoking on asthma in adults was conducted at our center [33]. The study was undertaken to compare the indices of morbidity and control of asthma in 100 adult patients exposed to ETS (group 2), with 100 asthmatics not exposed (group 1). Exposure was established from the history of smoking by the patient's spouse and other close contacts. Indices of asthma control and morbidity included the emergency department (ED) visits, hospitalization, acute episodes, requirement of parenteral drugs at home, corticosteroids, and maintenance bronchodilators in the preceding 1-year period. An index per patient was also calculated. Lung function was recorded by the measurement of forced expiratory flows on the same day of the follow-up visit. The mean age and disease duration were comparable, but the expiratory flows were lower in the patients exposed to ETS. More patients in this group had required daily bronchodilators ( 66 percent) and intermittent corticosteroids (56 percent) than patients from the other group. The number of ED visits, acute episodes, and parenteral bronchodilators per patient were significantly more $(p<0.01)$ in group 2 patients. Similarly, the number of weeks of absence from work and of corticosteroids requirement were more $(\mathrm{p}<0.01)$ among the ETS-exposed patients (Table 1). Subsequently, we had studied the role of ETS exposure in causing acute exacerbations of asthma [34]. One hundred patients of asthma seen in the emergency room with an acute attack of less than 24 hour duration were interviewed for exposure to known asthma triggers including ETS in the preceding 24 hours and were compared with 100 stable patients of asthma. Sixty-seven patients with acute exacerbation could point to a possible triggering factor. There was a significantly higher prevalence of exposure to ETS in patients with acute exacerbations compared to stable asthmatics $(41 \%$ vs. $20 \%$; $\mathrm{p}<0.01)$. ETS was the only significant identifiable trigger for acute asthma in 33 ETS-exposed patients.

Bronchial hyper-responsiveness is central to pathophysiology of asthma. We have also studied the effect of chronic ETS exposure on bronchial responsiveness by measuring BHR in stable, nonsmoking asthmatic women and compared the $\mathrm{PD}_{20}$ in ETS exposed and unexposed patients [35]. Histamine broncho provocation test was performed on 50 patients with stable asthma, of whom 23 (46\%) were exposed to ETS (mean exposure $1.22 \pm 0.61$ hours/day for $13.07 \pm 6.1$ years). The $\mathrm{PD}_{20}$ was significantly lower in the ETS-exposed than in unexposed group (mean $5.66 \pm 9.62$ vs. $11.8 \pm 13.06$ units, median 1.7 vs. 6.1 units). The morbidity indices in the ETS group were also worse than in the control group. It is, therefore, likely that continued and chronic ETS exposure, especially when heavy, worsens asthma control by exacerbation of BHR. The adverse effects of ETS on asthma are corroborated by several inhalation challenge studies [36,37]. 
Table 1. Indices of asthma control (per patient in the preceding 1 year) in ETS exposed and unexposed asthmatic patients

\begin{tabular}{lcc}
\hline & $\begin{array}{c}\text { Group 1 } \\
(\mathrm{n}=100)\end{array}$ & $\begin{array}{c}\text { Group 2 } \\
(\mathrm{n}=100)\end{array}$ \\
\hline Emergency department visits & 0.6 & $0.82^{*}$ \\
Hospitalization & 0.33 & 0.34 \\
Acute episodes & 0.6 & $1.32^{*}$ \\
Parenteral bronchodilators (no.) & 6.0 & $8.6^{*}$ \\
Absence from work (weeks) & 3.0 & $3.6^{*}$ \\
Steroid requirement (weeks) & 8.6 & $11.3^{*}$ \\
Bronchodilators requirement (weeks) & 36.3 & 38.3 \\
\hline
\end{tabular}

$*$ p $<0.01$; Group 1 = Not exposed to ETS; Group 2= Exposed to ETS (Reproduced with permission from reference 33 ).

\section{PASSIVE SMOKING AND RESPIRATORY SYMPTOMS IN CHILDREN}

Passive smoking increases the risk of lower respiratory tract infections such as bronchitis, pneumonia and bronchiolitis in children. The International Consultation report [23] concluded that parental smoking is an important cause of lower respiratory tract illnesses (e.g. croup, bronchitis, bronchiolitis, and pneumonia) during the first years of life. Of over 40 studies, all but one, have reported an increased risk among children whose parents smoke. Pooling the studies' results, children whose mothers smoke are estimated to have a 1.7 -fold ( $95 \% \mathrm{CI}=1.6-1.9)$ higher risk of these illnesses than children of nonsmoking mothers. Paternal smoking alone causes a 1.3 -fold $(95 \% \mathrm{CI}=1.2-1.4)$ increase in risk. This result shows a strong evidence for a causal role of ETS exposure, since it is uncomplicated by maternal smoking during pregnancy. Similar effects were also seen for both wheezing and non-wheezing illnesses, and across studies done in communities and hospitals. In an asthma prevalence study we mentioned before [25], 31\% of students reported the presence of one or more respiratory symptoms. ETS was also positively associated with prevalence of all respiratory symptoms, with odds ratios varying between 1.6 and 2.25 (Table 2). Similarly, a study was carried out to find out the prevalence and common causes of chronic/recurrent cough among rural children in Ludhiana (Punjab), India [38]. The prevalence of cough was $1.06 \%$ among a study sample of 2275 children. Asthma was the commonest cause of this cough (66.7\%) followed by post-nasal drip (25\%). Significantly, the family history of smoking was present in $16.7 \%$ of children with cough compared to $6.4 \%$ of children without cough.

Table 2. Prevalence of respiratory symptoms and asthma with reference to ETS exposure at home

\begin{tabular}{|c|c|c|c|c|}
\hline & \\
\hline & $\begin{array}{c}\text { Exposed } \\
(\mathrm{n}=2574)\end{array}$ & $\begin{array}{l}\text { Unexposed } \\
(\mathrm{n}=6516)\end{array}$ & $\begin{array}{l}\text { Crude O.R. } \\
(95 \% \text { C.I. })^{*}\end{array}$ & $\begin{array}{l}\text { Age and sex adjustedO.R. } \\
(95 \% \text { C.I. }) *\end{array}$ \\
\hline Asthma (questionnaire diagnosis) & $84(3.3 \%)$ & $121(1.9 \%)$ & $1.783(1.345-2.364)$ & $1.780(1.340-2.364)$ \\
\hline \multicolumn{5}{|l|}{ Symptoms } \\
\hline Wheeze & $226(8.8 \%)$ & $364(5.6 \%)$ & $1.627(1.369-1.933)$ & $1.605(1.349-1.910)$ \\
\hline Chest tightness & $220(8.5 \%)$ & $345(5.3 \%)$ & $1.671(1.402-1.992)$ & $1.690(1.417-2.017)$ \\
\hline Dyspnea on exertion & $425(16.5 \%)$ & $676(10.4 \%)$ & $1.708(1.499-1.948)$ & $1.689(1.481-1.927)$ \\
\hline Dyspnea at rest & $129(5.0 \%)$ & $207(3.2 \%)$ & $1.608(1.284-2.013)$ & $1.671(1.333-2.095)$ \\
\hline Dyspnea at night & $134(5.2 \%)$ & $205(3.1 \%)$ & $1.690(1.353-2.112)$ & $1.702(1.360-2.129)$ \\
\hline Cough at night & $355(13.8 \%)$ & $556(8.5 \%)$ & $1.715(1.488-1.976)$ & $1.754(1.521-2.023)$ \\
\hline Cough in morning & $210(8.2 \%)$ & $308(4.7 \%)$ & $1.790(1.493-2.047)$ & $1.763(1.469-2.117)$ \\
\hline Phlegm in morning & $384(14.9 \%)$ & $586(9.0 \%)$ & $1.773(1.545-2.035)$ & $1.761(1.533-2.023)$ \\
\hline Phlegm for $>3$ months & $152(6.7 \%)$ & $224(4.0 \%)$ & $1.698(1.374-2.099)$ & $1.719(1.388-2.129)$ \\
\hline Chest tightness on exposure to allergens & $425(16.5 \%)$ & $526(8.1 \%)$ & $2.252(1.964-2.583)$ & $2.245(1.956-2.577)$ \\
\hline Dyspnea on exposure to allergens & $432(16.8 \%)$ & $658(10.1 \%)$ & $1.796(1.575-2.047)$ & $1.881(1.648-2.147)$ \\
\hline
\end{tabular}

* Odds ratio and 95\% confidence interval (Reproduced with permission from reference 25). 


\section{PASSIVE SMOKING AND LUNG CANCER}

Nonsmoking individuals with long-term ETS-exposure have an increased risk of lung cancer. Hackshaw et al. reviewed 37 epidemiological studies on the risk of lung cancer in nonsmoking persons (4626 cases) [39]. It was found that lifetime risk of lung cancer in nonsmoking persons who lived with a smoker was $24 \%$ (95\% CI $13 \%$ to $20 \%$ ). Tobacco specific carcinogens have also been detected in the blood of the ETS exposed nonsmoking persons providing clear evidence of the ETS association. A dose-response relationship between the nonsmoker's risk of lung cancer and cumulative exposure to ETS was also demonstrated in this review [39]. More recently, Taylor and colleagues have done a cumulative meta-analysis incorporating 43 studies (meeting their inclusion criteria from a total 76 primary epidemiological studies and 20 meta-analyses reported between 1981 and 1999) [40]. The pooled relative risk (RR) for never-smoking women exposed to ETS from spouses, compared with unexposed never-smoking women was 1.29 (95\% CI 1.17-1.43).

In our experience, active smoking remains the strongest risk factor for developing lung cancer particularly among men. The association of lung cancer with smoking seems to be weaker in women as compared to men; an observation based on a study that only about one third of our female patients with lung cancer were smokers compared to nearly $90 \%$ of men with such malignancies [41]. In a recent study by us, we have interviewed 265 histologically confirmed lung cancer patients (235 men, 30 women) and 525 hospital controls (435 men, 90 women) matched for age and sex, by a predesigned questionnaire. The effects of individual variables defining various aspects of tobacco smoking, indoor and outdoor air pollution and occupational exposure were assessed using unconditional logistic regression models. Eighty nine per cent of men and 33 per cent of women among the patients were ever-smokers as compared to 60 per cent of men and 20 per cent of women among the controls. The Odds Ratio (OR) for ever-smoking was 5.0 (CI 3.11-8.04) among men and 2.47 (CI 0.79-7.75) among women [42]. We have looked into the role of passive smoking in 58 histologically proven cases of nonsmokers' lung cancer using a case-control study with two age-and-sex matched controls per each patient [43]. Subjects were asked about their ETS exposure from different tobacco products beginning from childhood onwards at home, at workplace and in vehicles. Multivariable logistic analysis was done to assess the effects of ETS exposure on lung cancer. Exposure to ETS during the childhood was strongly associated with lung cancer $(\mathrm{OR}=3.9$, 95\% CI 1.98.2) (Fig. 1). Restricting the analysis to women produced higher estimates of the risk $(\mathrm{OR}=12,95 \% \mathrm{CI} 4.3-32)$. The

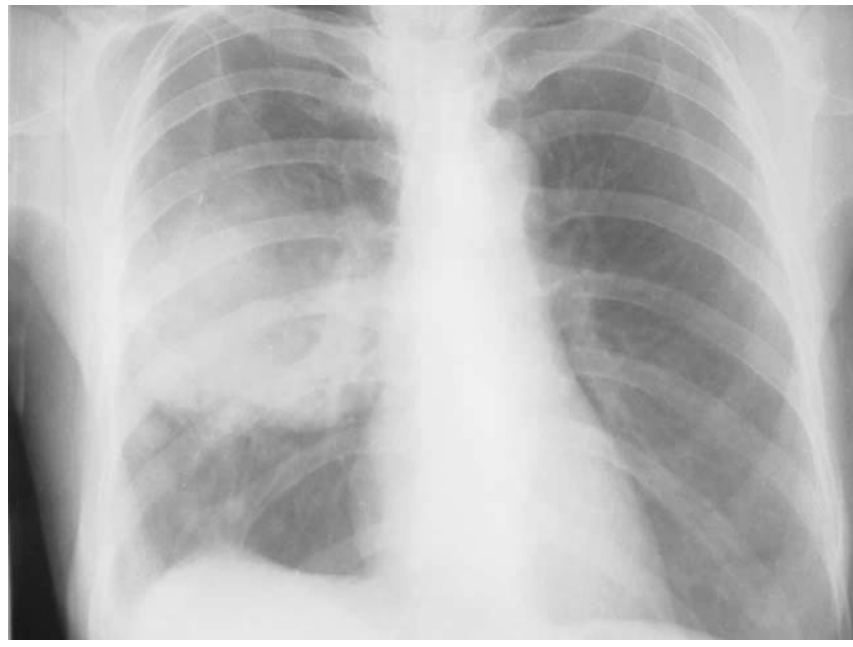

Fig. 1. A chest roentgenogram (PA view) of a non-smoking housewife with prolonged history of ETS exposure from father and spouse showing a mass lesion in right mid-zone, which turned out to be bronchogenic squamous cell carcinoma.

observed risk was higher for ETS exposure through cigarettes as compared to bidis or chilum; a finding that is consistent with the observation of comparative composition of MS and SS smoke from different tobacco products as mentioned before [6]. A weaker association was seen between lung cancer and ETS exposure from spouse, at workplace and in vehicles. Another interesting observation was made in the earlier collaborative study of the International Agency for Research on Cancer (IARC) in Chandigarh as one of the study centers [44]. Some of the excess risk of lung cancer development in nonsmoking women from spousal smoking was attributable to the childhood ETS-exposure from parental smoking. It was also shown that indeed daughters of smoking parents more often tended to marry smokers (71\% of women with smoking husbands had one or both parents smoking compared to $60.3 \%$ of women married to nonsmokers, who had at least one smoking parent; OR for the daughter of a smoker to marry a smoker was $1.64,95 \% \mathrm{CI}=1.24-2.17$ ), thus compounding the effects of parental and spousal ETS exposure. Therefore, ETS exposure, which is a recognized risk factor in countries with high prevalence of smoking, is also a risk factor in India, which historically has a low prevalence of smoking and lung cancer [45].

To summarize, passive smoking has several subtle as well as overt pulmonary effects. It is an established risk factor for lung cancer in nonsmoking persons. It is a significant risk factor for the respiratory symptoms and asthma in children. It is associated with an increased morbidity from asthma in adults, which is difficult to control. Passive smoking can also lead to a poor lung function, small airway dysfunction, and increased bronchial hyper-responsiveness in asymptomatic nonsmokers. 


\section{REFERENCES}

1. U.S. Department of Health and Human Services. The health consequences of involuntary smoking. DHHS(PHS) 878398. Washington, DC: USGPO, 1984.

2. US Environmental Protection Agency. Respiratory health effects of passive smoking: Lung cancer and other disorders. Publication EPA/600/6-90/006F.Washington, DC: US Environmental Protection Agency, Office of Air and Radiation, 1992.

3. Masironi R, Rothwell K. Trends in and effects of smoking in the world. World Health Statistics Quarterly 1988; 41: 228-241

4. Fielding, JE and Phenow, KJ. Health effects of involuntary smoking. New England Journal of Medicine 1988; 319: 14521460.

5. U.S. Department of Health and Human Services, Environmental Protection Agency. Respiratory health effects of passive smoking: lung cancer and other disorders (Smoking and Tobacco Control Monograph 4). NIH Publication No. 93-3605. Washington, DC: DHHS, 1993.

6. Pakhale SS, Maru GB. Distribution of major and minor alkaloids in tobacco, mainstream and sidestream smoke of popular Indian smoking products. Food and Chemical Toxicology 1998, 36: 1131-1138.

7. Srivastava PK, Pandit GG, Sharma S, Mohan Rao AM. Volatile organic compounds in indoor environments in Mumbai, India. The Science of Total Environment 2000; 255: 161-168.

8. Riboli E, Preston-Martin S, Saracci R, Haley NJ, Trichopoulos D, Becher H, Burch JD, Fontham ET, Gao YT, Jindal SK, Koo LC, Marchand LL, Segnan N, Shimizu H, Stanta G, WuWilliams AH, Zatonski W. Exposure of nonsmoking women to environmental tobacco smoke: a 10-country collaborative study. Cancer Causes and Control. 1990; 1: 243-252.

9. Ribloi E, Haley NJ, Tredaniel J, Saracci R, Preston-Martin S, Trichopoulos D. Misclassification of smoking status among women in relation to exposure to environmental tobacco smoke. European Respiratory Journal 1995; 8: 285-290.

10. Dayal HH, Khuder S, Sharrar R, Trieff N. Passive smoking in obstructive respiratory diseases in an industrialized urban population. Environmental Research 1994; 65:161-171.

11. Xu X, Li B. Exposure-response relationship between passive smoking and adult pulmonary function. American Journal of Respiratory and Critical Care Medicine 1995; 151: 41-46.

12. Smith CJ, Sears SB. Respiratory effects of secondhand smoke (letter). Journal of American Medical Association 1999; 281: 1083.

13. Behera D, Sood P, Singhi S. Passive smoking, domestic fuels and lung function in north Indian children. Indian Journal of Chest Diseases and Allied Sciences 1998; 40: 89-98.

14. Taylor RG, Joyce H, Gross E, Holland F, Pride NB. Bronchial reactivity to inhaled histamine and annual rate of decline in FEV1 in male smokers and ex-smokers. Thorax. 1985; 40: 9-16.

15. O'Connor GT, Sparrow D, Weiss ST. The role of allergy and nonspecific airway hyperresponsiveness in the pathogenesis of chronic obstructive pulmonary disease. American Review of Respiratory Disease 1989; 140: 225-252.
16. Jindal SK, Gupta D, D’souza GA, Kalra S. Bronchial responsiveness of non-smoking women exposed to environmental tobacco smoke or biomass fuel combustion. Indian Journal of Medical Research 1996; 104 : 359 -364.

17. Svendson KH, Kullar LH, Martin MJ, Ockene. Effects of passive smoking in the multiple risk factor intervention trial. American Journal of Epidemiology 1987; 126: 783-795.

18. Hole DJ, Gillis CR, Chopra C, Hawthorne VM. Passive smoking and cardiorespiratory health in a general population in the west of Scotland. British Medical Journal 1989; 299: 423-427.

19. White JR, Froeb HF. Small-airways dysfunction in nonsmokers chronically exposed to tobacco smoke. New England Journal of Medicine 1980; 302: 720-723.

20. Kaufmann F, Tessier JF, Oriol P. Adult passive smoking in the home environment: a risk factor for chronic airflow limitation. American Journal of Epidemiology 1983; 117: 269-280.

21. Malo JL, Leblanc P. Functional abnormalities in young asymptomatic smokers with special reference to flow volume curves breathing various gases. American Review of Respiratory Disease 1975; 111: 623-629.

22. Jindal SK, Gupta D. Environmental tobacco smoke and asthma. Indian Journal of Chest Diseases and Allied Sciences 1995; 37: 203-207.

23. International Consultation on Environmental Tobacco Smoke (ETS) and Child Health, 11-14 January 1999, Geneva, Switzerland. Consultation Report (document WHO/NCD/TFI/99.10). The background papers for the Consultation are available as document WHO/NCD/TFI/99.11. Geneva: WHO, 1999.

24. Neuspiel DR, Rush D, Butler NR, Golding J, Bijur PE, Kurzon M. Parental smoking and post-infancy wheezing in children: a prospective cohort study. American Journal of Public Health 1989; 79: 168-171.

25. Gupta D, Aggarwal AN, Kumar R, Jindal SK. Prevalence of Bronchial asthma and association with environmental tobacco smoke exposure in adolescent school children in Chandigarh, North India. Journal of Asthma 2001; 38: 501-507.

26. Jindal SK, Gupta D, Aggarwal AN, Jindal RC, Singh V. Prevalence of asthma in North India using a standardized field questionnaire. Journal of Asthma 2000; 34: 345-351.

27. The International Study of Asthma and Allergies in Childhood (ISAAC) Steering Committee: Worldwide variations in the prevalence of symptoms of asthma, allergic rhinoconjunctivitis and atopic eczema: ISAAC. Lancet 1998;. 351: 1225-1232.

28. Pokharel PK, Kabra SK, Kapoor SK, Pandey RM. Risk factors associated with bronchial asthma in school going children of rural Haryana. Indian Journal of Pediatrics 2001; 68: 103-106.

29. Ratageri VH, Kabra SK, Dwivedi SN, Seth V. Factors associated with severe asthma. Indian Paediatrics 2000; 37: 10721082.

30. Pedreira FA, Guandolo VL, Feroli EJ. Involuntary smoking and incidence of respiratory illness during the first year of life. Paediatrics 1985; 75: 594-595.

31. Strachan DP, Cook DG. Parental smoking and childhood asthma: longitudinal and case control studies. Thorax 1998; 53: 381-387. 
32. Cockcroft DW. Cigarette smoking, airway hyperresponsiveness, and asthma. Chest 1988; 94: 675-676.

33. Jindal SK, Gupta D, Singh AJ. Indices of morbidity and control of asthma in patients exposed to environmental tobacco smoke. Chest 1994; 106: 746-749.

34. Jindal SK, Gupta D, Chattopadhaya S, Kumar L. Environmental tobacco smoke exposure precipitates acute exacerbation in non smoker asthmatics. Lung India 1997; 15 : 168-172.

35. Jindal SK, Jha LK, Gupta D. Bronchial hyper-responsiveness of women with asthma exposed to environmental tobacco smoke. Indian Journal of Chest Diseases and Allied Sciences 1999; 40: 75-82.

36. Dahms TE, Bolin JF, Slavin RG. Passive smoking. Effects on bronchial asthma. Chest 1981; 80: 530-534.

37. Stankus RP, Menon PK, Rando RJ, Glindmeyer H, Salvaggio JE, Lehrer SB. Cigarette smoke-sensitive asthma: challenge studies. Journal of Allergy and Clinical Immunology 1988; 82: 331-8.

38. Singh D, Arora V, Sobti PC. Chronic/recurrent cough in rural children in Ludhiana, Punjab. Indian Pediatrics 2002; 39: 23-29.

39. Hackshaw AK, Law MR and Wald NJ. The accumulated evidence on lung cancer and environmental tobacco smoke. British Medical Journal 1997; 315: 980-988.
40. Taylor R, Cuming R, Woodward A, Black M. Passive smoking and lung cancer: a cumulative meta analysis. Australian and New Zealand Journal of Public Health 2001; 25: 203 - 211.

41. Behera D. Lung cancer in India. Indian Journal of Chest Diseases and Allied Sciences 1992; 34: 91-101.

42. Gupta D, Boffetta P, Gaborieau V, Jindal SK,. Risk factors for lung cancer in Chandigarh, India. Indian Journal of Medical Research 2001; 113: 142-150.

43. Rapiti E, Jindal SK, Gupta D, Boffetta P. Passive smoking and lung cancer in Chandigarh, India. Lung Cancer 1999; 23: 183189.

44. Riboli E, Haley NJ,Tredaniel J, Saracci R, Preston-Martin S, Trichopoulos D, Becher H, Burch JD, Fontham ET, Gao YT, Jindal SK, Koo LC, Marchand LL, Segnan N, Shimizu H, Stanta G, Wu-Williams AH, Zatonski Wl. Do the nonsmoking daughters of smokers tend to marry smokers? Implications for epidemiological research on environmental tobacco smoke: The IARC collaborative study. Cancer Epidimiology, Biomarkers and Prevention 1995; 4: 821-824.

45. Parkin DM, Sasco AJ. Lung cancer: worldwide variation in occurrence and proportion attributable to tobacco use. Lung Cancer 1993; 9: 1-16. 